\title{
Activated Carbons Containing Dispersed Metal Oxide Particles for Removal of Methyl Mercaptan in Air
}

\author{
Hisashi Tamai", Miki Nakamori, Masayoshi Nishikawa, Takeshi Shiono \\ Department of Applied Chemistry, Graduate School of Engineering, Hiroshima University, Higashi-hiroshima, Japan. \\ Email: tamai@hiroshima-u.ac.jp
}

Received October $15^{\text {th }}$, 2010; revised December 21 ${ }^{\text {st }}, 2010$; accepted January $6^{\text {th }}, 2011$.

\begin{abstract}
Activated carbons containing dispersed metal oxide particles were prepared by carbonization of phenol resin containing metal compounds followed by steam activation. Acetylacetonates of Fe, Mn and V, and Cu nitrate were used as the sources of metals. The removal of a small amount of methyl mercaptan $\left(\mathrm{CH}_{3} \mathrm{SH}\right)$ in air with these activated carbons was tested in a flow system. Compared with activated carbons without metal oxides, the carbons exhibited high activity for the removal of $\mathrm{CH}_{3} \mathrm{SH}$ in air. In particular, activated carbon obtained from Novolac containing $5 \mathrm{wt} \% \mathrm{Cu}$ showed excellent behavior over a long time.
\end{abstract}

Keywords: Activated Carbon, Methyl Mercaptan, Adsorption, Metal Oxide, Oxidation

\section{Introduction}

Methyl mercaptan $\left(\mathrm{CH}_{3} \mathrm{SH}\right)$ is an odorous gas emitted to the atmosphere. Even a very small amount of $\mathrm{CH}_{3} \mathrm{SH}$ in air makes life uncomfortable, and its removal is important. For the removal of $\mathrm{CH}_{3} \mathrm{SH}$, various procedures have been investigated and applied. For instance, the adsorptive removal of $\mathrm{CH}_{3} \mathrm{SH}$ by activated carbon is one of the effective methods, because activated carbons with large specific surface area have high adsorption ability for a very low concentration of harmful gases. In practice, activated carbons have been widely used for the removal of odorous gases [1-6]. However, in most cases, their adsorption activity is lost due to saturated adsorption. This limitation suggests that they are inefficient for practical use for a long period. On the other hand, it is known that some metal oxides possess high catalytic activity for oxidative decomposition of organic compounds such as odorous substances [7-10]. From this point of view, regarding the limitation of activated carbons and the catalytic activity of metal oxides, it is expected that metal oxide particles dispersed in activated carbons may have improved functions both for adsorption and oxidative decomposition. As a result, these hybrid materials are expected to be very effective for the removal of $\mathrm{CH}_{3} \mathrm{SH}$ in air for long times.

Activated carbons containing metal oxides are gener- ally manufactured by impregnation metal compounds into activated carbons. However, this method decreases the surface area of the activated carbon, that is, the deposition of metal oxide particles on the pores lowers adsorption capacity. In addition, the supporting of metal oxide particles on the surface of the activated carbons is often irregular and the size of metal oxide particles is not necessarily uniform. Here, the simple preparation of metal oxides dispersed on activated carbons was investigated. The removal of a small amount of $\mathrm{CH}_{3} \mathrm{SH}$ in air by the activated carbons obtained was tested using $\mathrm{CH}_{3} \mathrm{SH} /$ air mixed gas in a flow method.

\section{Experimental}

Metal oxides dispersed in activated carbons were prepared by carbonization of phenol resins containing metal compounds followed by activation. Acetylacetonates of $\mathrm{Fe}, \mathrm{Mn}$, and $\mathrm{V}$, and $\mathrm{Cu}$ nitrate were used. Phenol resins containing metal compounds were prepared by mixing a methanol solution of Novolac with metal compounds dissolved in methanol. After mixing, methanol was removed by flash distillation and then cured at $170^{\circ} \mathrm{C}$ for 1 $\mathrm{h}$. The cured mixtures were carbonized in Ar atmosphere at $800^{\circ} \mathrm{C}$ for $1 \mathrm{~h}$, and then activated at $900^{\circ} \mathrm{C}$ for $1 \mathrm{~h}$. Activation was conducted with $\mathrm{N}_{2}$ gas saturated with steam.

The pore characteristics were determined from $\mathrm{N}_{2}$ ad- 
sorption/desorption isotherms using a Quantachrome NOVA 3200 apparatus. Metal contents in the activated carbons were determined by particle induced X-ray emission analysis (PIXE). The kinds of metal oxides were determined by X-ray diffraction (XRD). Metal oxides in the activated carbons were observed by transmission electron microscopy (TEM) and electron probe microanalysis (EPMA).

The test for the removal of $\mathrm{CH}_{3} \mathrm{SH}$ in air was conducted by flowing air containing $\mathrm{CH}_{3} \mathrm{SH}$ through activated carbon powder in a quartz tube of inner diameter of $4 \mathrm{~mm}$. Typically $10 \mathrm{mg}$ of activated carbon was placed in the tube. The inlet concentration of $\mathrm{CH}_{3} \mathrm{SH}$ in the air was $10 \mathrm{ppm}$. The amounts of $\mathrm{CH}_{3} \mathrm{SH}$ adsorbed and oxidized were obtained from the differences between the inlet concentration of $\mathrm{CH}_{3} \mathrm{SH}$ and the outlet one.

\section{Results and Discussion}

Various activated carbons were prepared from Novolac containing $1.0 \mathrm{wt} \%$ of $\mathrm{Fe}$ (AC-Fe-1), $1.0 \mathrm{wt} \%$ of $\mathrm{V}$ (AC-V-1), and $1.0 \mathrm{wt} \%$ of Mn (AC-Mn-1), and various wt $\%$ of $\mathrm{Cu}$ (AC-Cu-1, -2, -5, and -10). The $\mathrm{N}_{2}$ adsorption and desorption isotherms of the activated carbons obtained are shown in Figure 1 and Figure 2, respectively. Figure 1 also shows the isotherm of the activated carbon obtained from metal-free phenol resin (AC). As shown in Figure 1, the major uptake of $\mathrm{N}_{2}$ on AC occurs at relatively low relative pressure $(<0.2)$. This indicates that $\mathrm{AC}$ is microporous. On the other hand, in the case of AC-Fe-1, AC-V-1, and AC-Mn-1, the amounts of $\mathrm{N}_{2}$ adsorbed gradually increase with increasing relative pressure at relative pressure above 0.3 , and a hysteresis was observed between the adsorption and desorption isotherms of $\mathrm{N}_{2}$. In addition, in the case of AC-Mn-1, a steep increase in the amount of $\mathrm{N}_{2}$ adsorbed was observed at a high relative pressure of $0.8 \sim 1.0$. The formation of macropores is indicated in AC-Mn-1. These

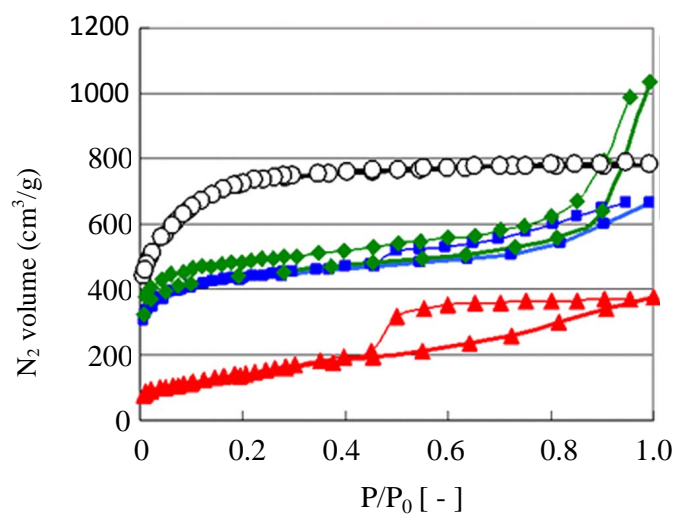

Figure 1. $\mathrm{N}_{2}$ adsorption/desorption isotherms of activated carbons obtained from phenol resin containing metal compounds. $\bigcirc$ : AC, $\triangle$ : AC-Fe-1, $₫$ : AC-V-1, $\diamond$ : AC-Mn-1.

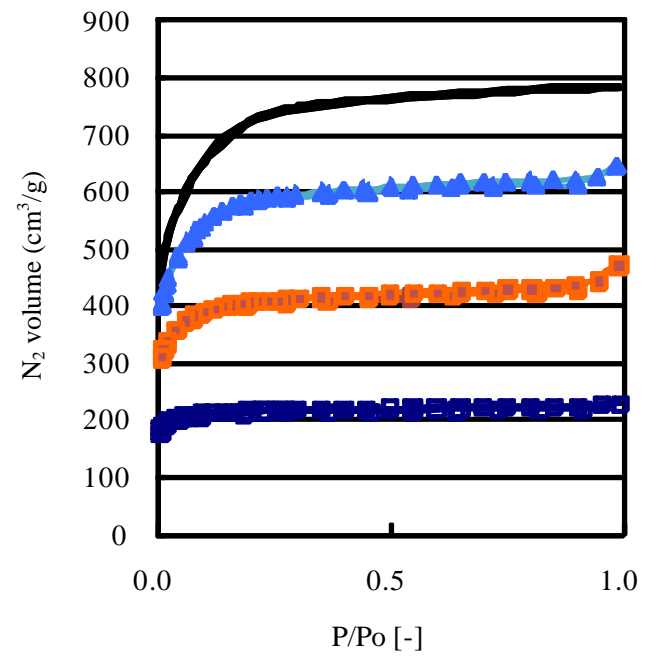

Figure 2. $\mathrm{N}_{2}$ adsorption/desorption isotherms of activated carbons obtained from phenol resin containing $\mathrm{Cu}\left(\mathrm{NO}_{3}\right)_{2} \cdot$-: AC, $\triangle$ : AC-Cu-1, $\square$ : AC-Cu-2, $\square$ : AC-Cu-10.

results suggest that the activated carbons obtained from phenol resin containing metal compounds are mesoporous and macroporous. We have earlier reported the preparation of mesoporous activated carbons by carbonization of polymer materials containing metal complexes followed by activation, and metal oxide particles in carbonaceous materials play an important role in mesopore formation [11]. Similarly to those results, mesopores seem to be formed by metal oxide particles in carbonaceous materials. However, in the case of AC-Cu shown in Figure 2, an increase in the amounts of $\mathrm{N}_{2}$ adsorbed at a relative pressure above 0.3 and a hysteresis between the adsorption and desorption isotherms were not observed, in spite of the increase in $\mathrm{Cu}$ content in phenol resin. AC-Cu are thought to be microporous.

Table 1 shows the pore characteristics. BET specific surface areas decreased by the addition of metal compounds to phenol resin. This is especially noticeable in AC-Fe-1. It is supposed that the decrease in BET specific surface area is attributed to the catalytic effect of metal oxide particles for steam activation. That is, the catalytic effect of metal oxides for steam activation excessively accelerate the activation, and as a result, pores formed in the carbons are lost by activation. The BET specific surface area of AC-Cu decreased with an increase in $\mathrm{Cu}$ content in Novolac. Table 1 also shows metal contents and metal species in the activated carbons. 3.8-6.0 wt\% of metal is contained in the activated carbons obtained from phenol resin containing $1.0 \mathrm{wt} \%$ of metal. These metal contents, determined by PIXE analysis, are comparable to the amounts calculated from the carbon yields after carbonization and activation. $\mathrm{Cu}$ contents in $\mathrm{AC}-\mathrm{Cu}$ increased with increasing $\mathrm{Cu}$ content in the phenol resin. 
Table 1. Characteristics of activated carbons containing dispersed metal oxide particles.

\begin{tabular}{|c|c|c|c|c|c|}
\hline Sample & $\begin{array}{c}\text { Metal amount } \\
\text { in novolac (wt } \%)\end{array}$ & $\begin{array}{l}\text { Metal amount } \\
\text { in AC (wt\%) }\end{array}$ & Metal species & $\begin{array}{c}\text { BET-SA } \\
\left(\mathrm{m}^{2} / \mathrm{g}\right)\end{array}$ & $\begin{array}{c}\text { Total porevolume } \\
\left(\mathrm{cm}^{3} / \mathrm{g}\right)\end{array}$ \\
\hline $\mathrm{AC}$ & - & - & - & 2597 & 1.20 \\
\hline AC-Fe-1 & 1.0 & 3.8 & $\mathrm{Fe}_{2} \mathrm{O}_{3}$ & 441 & 0.58 \\
\hline AC-V-1 & 1.0 & 4.5 & $\mathrm{VO}_{2}$ & 1610 & 1.00 \\
\hline AC-Mn-1 & 1.0 & 6.0 & $\mathrm{MnO}, \mathrm{MnO}_{2}$ & 1670 & 1.60 \\
\hline AC-Cu-1 & 1.0 & 4.1 & $\mathrm{CuO}, \mathrm{Cu}_{2} \mathrm{O}$ & 2160 & 1.00 \\
\hline AC-Cu-2 & 2.0 & 4.5 & $\mathrm{CuO}, \mathrm{Cu}_{2} \mathrm{O}$ & & 0.73 \\
\hline AC-Cu-5 & 5.0 & 16.4 & $\mathrm{CuO}, \mathrm{Cu}_{2} \mathrm{O}$ & & 0.48 \\
\hline AC-Cu-10 & 10.0 & 34.0 & $\mathrm{Cu}, \mathrm{CuO}, \mathrm{Cu}_{2} \mathrm{O}$ & & 0.35 \\
\hline
\end{tabular}

These results suggest that the amounts of metal contained in phenol resin are retained in the ACs even after activation. Metal species formed in the activated carbons were determined by XRD. The formation of metal oxides was observed (XRD profiles are not shown). $\mathrm{Fe}_{2} \mathrm{O}_{3}$ in AC-Fe-1, $\mathrm{VO}_{2}$ in AC-V-1, $\mathrm{MnO}$ and $\mathrm{MnO}_{2}$ in AC-Mn-1, $\mathrm{CuO}$ and $\mathrm{Cu}_{2} \mathrm{O}$ in $\mathrm{AC}-\mathrm{Cu}-1$. The dispersion of metal oxide particles in activated carbons was observed by TEM and EPMA. Figure 3 shows the TEM and EPMA images of AC-Cu-5. The TEM image suggests that large copper oxide particles, greater than $50 \sim 100 \mathrm{~nm}$, are present. However, the EPMA image indicates that copper was uniformly dispersed in the activated carbon. It is supposed that various sizes of copper oxide particles are dispersed and very fine copper oxide particles which cannot be resolved by TEM are present in the activated carbon. Regarding the other metal compounds, similar results to copper were observed.

The removal of $\mathrm{CH}_{3} \mathrm{SH}$ in air was tested. Figure 4 shows the removal of $\mathrm{CH}_{3} \mathrm{SH}$ from air as a function of flow time of $\mathrm{CH}_{3} \mathrm{SH} /$ air gas mixture at $200 \mathrm{ml} / \mathrm{min}$ flow speed. Initially, $\mathrm{CH}_{3} \mathrm{SH}$ was efficiently removed. However, removal steeply decreased after 200 min flow time. This seems to be due to saturated adsorption of the AC. On the other hand, activated carbons with dispersing metal oxide particles, AC-Fe-1, AC-V-1, and AC-Mn-1, exhibited higher removal activities than AC over a long time. Figure 5 shows the removal of $\mathrm{CH}_{3} \mathrm{SH}$ from air by $\mathrm{AC}-\mathrm{Cu}$, as a function of flow time at $40 \mathrm{ml} / \mathrm{min}$ flow speed. The removal ratios by $\mathrm{AC}-\mathrm{Cu}-1, \mathrm{AC}-\mathrm{Cu}-2$, and

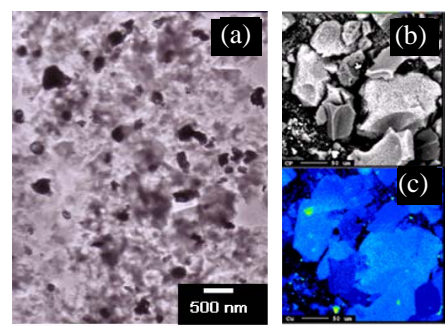

Figure 3. TEM, SEM, and EPMA images of AC-Cu-5. (a): TEM , (b): SEM, (c): EPMA.

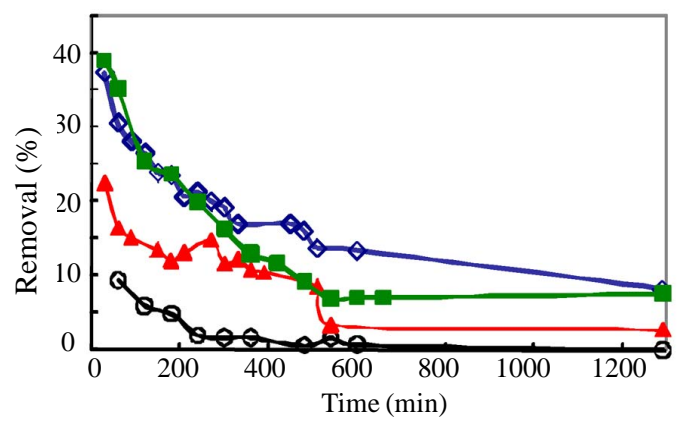

Figure 4. Removal of methyl mercaptan $\left(\mathrm{CH}_{3} \mathrm{SH}\right)$ in air by activated carbons containing dispersed metal oxide particles. Flow rate of $\mathrm{CH}_{3} \mathrm{SH} / \mathrm{Air}$ mixed gas: $200 \mathrm{ml} / \mathrm{min}$. $\bigcirc: \mathrm{AC}$, $\triangle:$ AC-Fe-1, $\diamond:$ AC-V-1, $\sqsubset:$ AC-Mn-1.

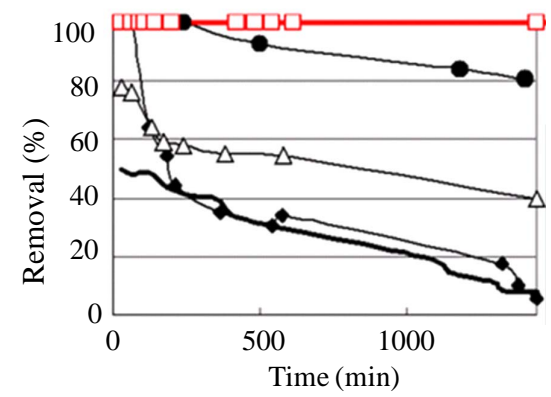

Figure 5. Removal of methyl mercaptan $\left(\mathrm{CH}_{3} \mathrm{SH}\right)$ in air by activated carbons containing dispersed copper oxide particles. Flow rate of $\mathrm{CH}_{3} \mathrm{SH} / \mathrm{Air}$ mixed gas: $40 \mathrm{ml} / \mathrm{min}$. -: $\mathrm{AC}$, $\diamond: A C-C u-1, \bullet: A C-C u-2, \square:$ AC-Cu-5, $\triangle$ : AC-Cu-10.

AC-Cu-5 increased with increase in $\mathrm{Cu}$ amount. These removal ratios of $\mathrm{CH}_{3} \mathrm{SH}$ by $\mathrm{AC}-\mathrm{Cu}$ are far higher than that by metal-free AC. Furthermore, it should be noted that AC-Cu-5, prepared from phenol resin containing 5.0 wt\% of $\mathrm{Cu}$, exhibited the highest removal activity and $\mathrm{CH}_{3} \mathrm{SH}$ in air was completely removed after $24 \mathrm{~h}$ flow time. On the relationship between surface areas of activated carbons and $\mathrm{Cu}$ contents in phenol resin, BET specific surface area decreased with increasing content of $\mathrm{Cu}$, as shown in Table 1. These results suggest that the removal of $\mathrm{CH}_{3} \mathrm{SH}$ in air is due to oxidative decomposition of $\mathrm{CH}_{3} \mathrm{SH}$ by copper oxide particles, in addition to 
adsorption by the activated carbon. It has been reported that metal oxides catalyze the oxidation of $\mathrm{CH}_{3} \mathrm{SH}$ to dimethyl disulfide $[8,9]$. Therefore, copper oxide particles dispersed in the activated carbons prepared in this work seem to have an extremely high efficiency for the oxidative decomposition of $\mathrm{CH}_{3} \mathrm{SH}$ in air. As a result, activated carbons with dispersed copper oxide particles are supposed to exhibit high activities for the removal of a small amount of $\mathrm{CH}_{3} \mathrm{SH}$ in air.

\section{Conclusions}

Activated carbons containing a fine dispersion of metal oxide particles were prepared by carbonization of phenol resin containing metal compounds followed by steam activation. These materials exhibited high activity for the oxidative removal of a small amount of $\mathrm{CH}_{3} \mathrm{SH}$ in air. In particular, the activity of activated carbon containing dispersed copper oxides was very high over a long time.

\section{REFERENCES}

[1] T. Sakano, H. Tamon and M. Okazaki, "Selective Removal of Methyl Mercaptan Coffee Aroma Using Oxidized Microporous Carbon,” Journal of Chemical Engineering of Japan, Vol. 32, No. 5, 1999, pp. 701-704. doi:10.1252/jcej.32.701

[2] A. K. Dalai, E. L. Tollefson, A. Yang and E. Sasaoka, "Oxidation of Methyl Mercaptan over an Activated Carbon in a Fixed-Bed Reactor," Industrial \& Engineering Chemistry Research, Vol. 36, No. 11, 1997, pp. 47264733. doi:10.1021/ie9701231

[3] S. Bashkova, A. Bagreev and T. J. Bandosz, "Adsorption of Methyl Mercaptan on Activated Carbons," Environmental Science \& Technology, Vol. 36, No. 12, 2002, pp. 2777-2782. doi:10.1021/es011416v

[4] S. Bashkova, A. Bagreev and T. J. Bandosz, "Effect of Surface Characteristics on Adsorption of Methyl Mercaptan on Activated Carbons," Industrial \& Engineering Chemistry Research, Vol. 41, No. 17, 2002, pp. 4346-
4352.

doi:10.1021/ie020137t

[5] S. Bashkova, A. Bagreev and T. J. Bandosz, "Adsorption/Oxidation of $\mathrm{CH}_{3} \mathrm{SH}$ on Activated Carbons Containing Nitrogen," Langmuir, Vol. 19, No. 15, 2003, pp. 6115-6121. doi:10.1021/la0300030

[6] A. Bagreev, J. A. Menendez, I. Dukhno, Y. Tarasenko and T. J. Bandoz, "Oxidative Adsorption of Methyl Mercaptan on Nitrogen-Enriched Bituminous Coal-Based Activated Carbon,” Carbon, Vol. 43, No. 1, 2005, pp. 195 $-213$. doi:10.1016/j.carbon.2004.09.003

[7] A. H. Miguel, D. F. S. Natusch, R. L. Tanner and J. L. Hudson, "Adsorption and Catalytic Conversion of Thiol Vapors by Activated Carbon and Manganese Dioxide," Atmospheric Environment, Vol. 10, No. 2, 1976, pp. 145 -150. doi:10.1016/0004-6981(76)90232-8

[8] C. J. Heyes, J. G. Irwin, H. A. Johnson and R. L. Moss, "The Catalytic Oxidation of Organic Air Pollutants. Part 1. Single Metal Oxide Catalysts," Journal of Chemical Technology \& Biotechnology, Vol. 32, No. 12, 1982, pp. 1025-1033. doi:10.1002/jctb.5030320746

[9] C. J. Heyes, J. G. Irwin, H. A. Johnson and R. L. Moss, "The Catalytic Oxidation of Organic Air Pollutants. Part 2. Cobalt Molybdate and Copper Chromite Catalysts," Journal of Chemical Technology \& Biotechnology, Vol. 32, No. 12, 1982, pp. 1034-1041.

[10] M. Nozawa, K. Tanigawa, M. Hosomi, T. Chikusa and E. Kawada, "Removal and Decomposition of Malodorants by Using Titanium Dioxide Photocatalyst Supported on Fiber," Water Science and Technology, Vol. 44, No. 9, 2001, pp. 127-133.

[11] H. Tamai, T. Kakii, Y. Hirota, T. Kumamoto and H. Yasuda, "Synthesis of Extremely Large Mesoporous Activated Carbon and Its Unique Adsorption for Giant Molecules," Chemistry of Materials, Vol. 8, No. 2, 1996, pp. 454-462. doi:10.1021/cm950381t 